\title{
Can a surgical treatment centre reduce waiting lists? Results of a natural experiment
}

\author{
Ian Harvey, Mary Webb, John Dowse
}

\begin{abstract}
Study objective-To determine the effectiveness of the Welsh general surgery (hernia and varicose veins) treatment centre established as part of the NHS reforms, in terms of its impact upon throughput and waiting lists. Design-This was a natural experiment with two control groups-other surgical specialties without treatment centre provision, and general surgery in districts that made only minor use of the facility.
\end{abstract}

Setting-General Surgery Treatment Centre, Bridgend General Hospital.

Subjects-All patients referred between 1 April 1990 and 31 March 1991.

Measurements and main results-Main outcome measures were throughput for hernia and varicose vein operations, non-urgent inpatient waiting list lengths before and after the opening of the centre and patient satisfaction. Altogether 1097 patients were referred during the year. Of these, 160 (15\%) did not attend outpatient assessment and 79 $(8 \%)$ of those who did were unsuitable for surgery. A total of 750 operations were performed-448 $(60 \%)$ for varicose veins and 261 (35\%) hernia repairs. Among the residents of the four main districts using the centre (with valid data available), there was a significant increase in the total number of varicose vein operations performed but no significant increase in hernia repairs. In the six districts that made major use of the centre, general surgery waiting lists for nonurgent cases fell significantly $(p<0 \cdot 0001)$ while those for ear, nose, and throat showed no significant change and gynaecology lists lengthened significantly $(p<0 \cdot 0001)$. In the three districts that made minor use of the centre general surgery waiting lists showed no change.

Conclusions-Relations between inputs and waiting lists are often unpredictable, but after controlling for confounding trends there is sound evidence that such a centre provides an acceptable and effective approach to the waiting list problem.

f Epidemiol Community Health 1993; 47: 373-376

Waiting lists, principally those for elective surgery, have been a source of considerable political and medical concern since the inception of the British National Health Service. ${ }^{1}$ The suggested causes have varied widely, ${ }^{2}$ ranging from the notion that excessive demand is inevitable when health care is substantially free at the point of delivery ${ }^{3}$ to the view that comparatively meagre health expenditure $^{4}$ is responsible. Others have emphasised the role of surgeons' clinical preferences. ${ }^{5}$ Suggested remedies have been equally diverse. The recent radical chages to the NHS are largely the result of concern in 1987-88 about waiting times for paediatric cardiac surgery.

Two points are worth emphasising. Firstly, patients on surgical waiting lists are largely awaiting relatively simple, cost effective treatments. ${ }^{6}$ Secondly, many of the suggested ways of reducing waiting lists have quite inexplicably failed to have any impact. ${ }^{7}$ Although providing additional faclities and staff should lead to the treatment of more patients and thus, in time, to a reduction in the length of waiting lists, this expectation has not often been met. ${ }^{8-10}$ The relationships between resources, throughput, and waiting lists are complex and highly unpredictable. It is thus essential that any waiting list initiative should be properly evaluated.

Despite its origins in a waiting list dispute, the only directly relevant proposal in the British Government's White Paper Working For Patients was that "special consideration will be given to the establishment of treatment centres to ensure the rapid turn-round of cases ...". ${ }^{11}$ This appeared only in the Welsh section of the paper. Although temporary facilities have been established in the United Kingdom to tackle long waiting lists in individual districts, ${ }^{12}$ the treatment centres that have been funded by the Welsh Office are unique in providing permanent, supradistrict facilities. Three were opened in 1990 and a fourth in 1991, each located within an existing hospital. A hip and knee replacement centre was contracted to perform 180 hip and 30 knee replacements in its first year and a cataract centre to perform 500 procedures annually. The general surgery centre in this study was established in South Wales (Bridgend General Hospital, Mid Glamorgan) in April 1990. In October 1991, a cataract centre opened in the same hospital.

The existence of these centres, which are intended to serve the whole population of Wales, is unknown to most surgeons elsewhere in the UK. They are of wider importance for three reasons. Firstly, they challenge the increasingly disputed ${ }^{13}$ view that waiting lists are an inevitable and unmanageable feature of a health service that is free at the point of delivery. Secondly, they test the publics' expressed willingness to travel long distances for elective treatment. ${ }^{14}$ Thirdly, they provide a rare opportunity to evaluate the impact of a discrete element of the NHS reforms upon a defined population by means of a natural experiment. ${ }^{15}$ 
In a natural experiment ${ }^{16}$ advantage is taken of the introduction of a programme to assess its effectiveness by examining the outcome in both intervention and appropriately selected control groups. In this instance two sets of comparisons may sensibly be made, with waiting list length as the primary outcome measure: (a) a "before and after" comparison between waiting lists in general surgery and other surgical specialties with no treatment centre provision and (b) a "before and after" comparison, confined to general surgery waiting lists, between health authorities that have made major use and those which have made little use of the centre.

The 14 bed General Surgery Treatment Centre opened in April 1990 in refurbished accommodation in a hospital for the elderly that had no intensive care facilities. There is a part-time consultant surgeon with junior doctor support. Revenue of $£ 539000$ was provided to fund a minimum of 800 hernia and varicose vein operations in the first year ( $£ 674$ per procedure). This throughput was intended to be additional to existing surgical activity.

Eligible patients are Welsh residents who have been on an inpatient waiting list for at least four months, with preference shown to those waiting more than one year. Referrals can come from either general practitioners or consultants. Residents of the host health authority should not constitute more than $20 \%$ of those treated.

Two preoperative asessment clinics are held weekly. Inpatients are usually admitted for two nights. The centre closes at weekends. Transport to and from the centre is the responsibility of the patient. There is no routine follow up after surgery.

The objectives of the study were to determine: the amount and type of surgical activity undertaken; the geographical origins of the patients referred; the proportion of the referred patients considered suitable for surgery; the level of patient satisfaction with the service; and the overall

Table I Surgical treatment centre: quarterly activity

\begin{tabular}{lccccr}
\hline & Apr-fune & fuly-Sept & Oct-Dec & fan-Mar & \\
& 1990 & 1990 & 1990 & 1991 & Total \\
\hline Total no of referrals: & 159 & 224 & 308 & 406 & 1097 \\
Failed to attend & 12 & 20 & 25 & 24 & 81 \\
Unable to attend & 20 & 23 & 17 & 19 & 79 \\
Patients seen: & 127 & 181 & 266 & 363 & 937 \\
Not suitable for operation & 11 & 16 & 16 & 36 & 79 \\
Failed to attend for operation & 0 & 3 & 5 & 2 & 10 \\
Unable to attend for operation & 2 & 6 & 3 & 8 & 19 \\
Unsuitable preoperation & 1 & 2 & 2 & 2 & 7 \\
No of patients for operation & 112 & 143 & 209 & 282 & 746 \\
\hline
\end{tabular}

Failed to attend-no explanation given

Unable to attend-explanation given

Table II Operations performed and districts of origin

\begin{tabular}{|c|c|c|c|c|c|c|}
\hline District & $\begin{array}{l}\text { Hernia } \\
B\end{array}$ & $U$ & $\underset{B}{\text { Varica }}$ & $\begin{array}{l}\text { e veins } \\
U\end{array}$ & Miscellaneous & $\begin{array}{l}\text { Total no of } \\
\text { operations (\%) }\end{array}$ \\
\hline South Glamorgan & 5 & 35 & 19 & 37 & 4 & $100(13)$ \\
\hline Powys & 0 & 3 & 2 & 8 & 1 & $14(2)$ \\
\hline Dyfed & 1 & 30 & 21 & 28 & 0 & $80(11)$ \\
\hline West Glamorgan & 4 & 64 & 25 & 30 & 0 & $123(16)$ \\
\hline Gwynedd & 0 & 0 & 3 & 1 & 0 & $4(0.5)$ \\
\hline Pembrokeshire & 2 & 11 & 16 & 16 & 0 & $45(6)$ \\
\hline Gwent & 0 & 12 & 7 & 7 & 0 & $26(3)$ \\
\hline Mid Glamorgan & 4 & 90 & 72 & 154 & 36 & $356(47)$ \\
\hline English districts & 0 & 0 & 1 & 1 & 0 & $2(0 \cdot 2)$ \\
\hline Total $(\%)$ & $\begin{array}{l}16 \\
(35)\end{array}$ & 245 & $\begin{array}{l}166 \\
(60)\end{array}$ & 282 & $\begin{array}{l}41 \\
(5)\end{array}$ & $\begin{array}{l}750^{\circ} \\
(100)\end{array}$ \\
\hline
\end{tabular}

$\mathrm{U}=$ unilateral procedure; $\mathrm{B}=$ bilateral procedure.

Total number of patients $=746$, four patients had two types of operation impact of the centre on throughput for these surgical procedures and on general surgery waiting list length.

\section{Methods}

Relevant data were available from both computerised (Marketshield, Marketshield Ltd, Birmingham, England) and manual sources. Patient satisfaction and certain other key outcomes were assessed by a 15 item questionnaire given to each patient on discharge from hospital. Staff at the centre had decided against follow up of those who did not respond. To assess the impact of the centre on the wider throughput for these procedures in Wales, patient episode data (PEDW) for these operations (non-emergency admissions with any mention of either OPCS 3 codes 410 , $411,412,415,419,891,893,894$; or OPCS 4 codes T19-T27 inclusive or L83 (omitting L83.1), L85, L86 or L87) broken down by age and health district of residence, were obtained covering the five financial years up to March 1991. Waiting list data were obtained from routine Welsh Office publications.

DATA ANALYSIS AND STATISTICAL METHODS Data were analysed using MINITAB PC statistical software (Minitab Inc, Pennsylvania, USA). Counts were compared, on the assumption that they followed a Poisson distribution, by generating a standardised normal deviate test statistic. ${ }^{17}$

\section{Results}

In the first year of operation (beginning 1 April 1990), 1097 patients were referred to the surgical treatment centre (table I). A total of 160 patients (15\%) did not attend their preoperative assessment appointment and 79 of 937 (8\%) patients assessed either did not require surgery or were not considered suitable because of comorbidity.

Altogether 782 patients were scheduled for operation during the first year. Twenty nine (4\%) did not attend and seven (1\%) were considered unsuitable. A total of 750 operations were performed (table II) (182 bilateral, 932 procedures in total). Some 448 of $750(60 \%)$ were for varicose veins, 261 of 750 (35\%) were hernia repairs, and the remainder included circumcisions and removal of epididymal cysts.

There was wide variation in the use made of the treatment centre by the residents of different health districts. The host district residents accounted for $48 \%$ of procedures performed. While geographical proximity was plainly a major determinant of utilisation there were other unexplained variations. Most strikingly, the number of patients treated from Pembrokeshire was substantially higher than that from Gwent, despite the fact that Pembrokeshire has only a quarter of the population and is more distant.

Amongst patients treated at the centre, children (under 10 years) and the elderly (over 70 years) were noticeably under-represented compared with those treated for the same conditions elsewhere in Wales.

The effectiveness of the treatment centre may be judged firstly by whether it has produced an 


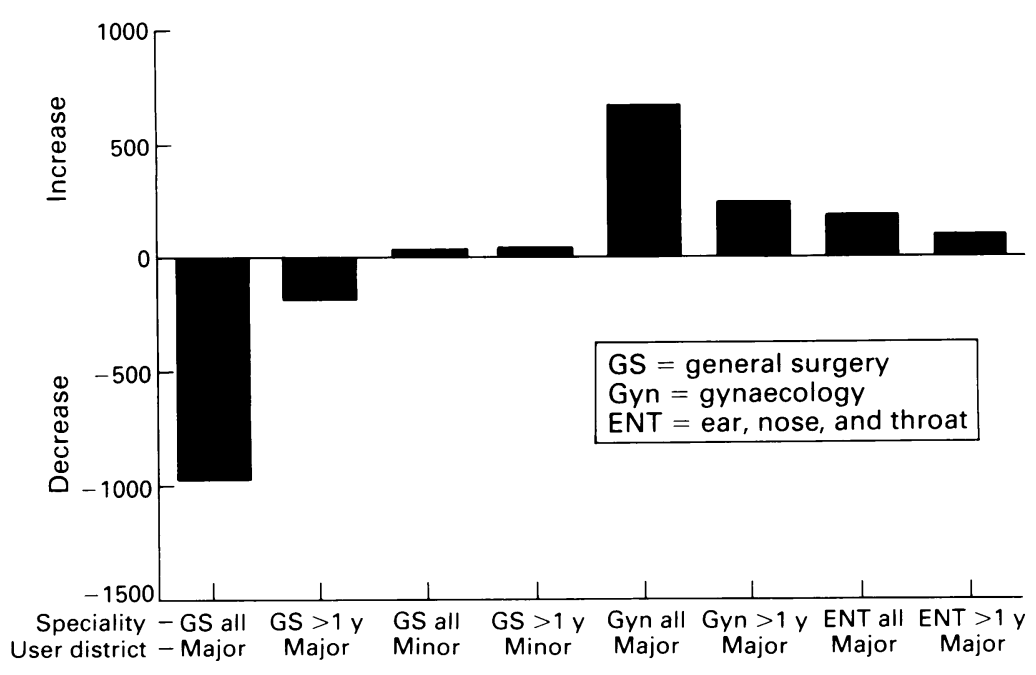

Changes in non-urgent waiting lists beforehand and one year after the centre opened.

overall increase in throughput for these surgical procedures and secondly, and more importantly, by its observed impact upon waiting lists.

ADDITIONAL THROUGHPUT OR SUBSTITUTION? PEDW were examined for those Welsh districts (1) which were major users of the centre (defined as treatment centre usage greater than $3 \%$ of that district's residents' throughput for these procedures in the previous financial year 1989/90), and (2) whose PEDW data were known to be without major errors. Four Welsh districts met both criteria (South and Mid Glamorgan, Powys, and Pembrokeshire, total population 1.2 million). For the residents of these districts there was a significant increase in the number of varicose vein operations performed in the year 1990-91 (the first year of operation of the centre) compared with the mean for the previous four years $(1986-90$ mean $=672,1990 / 91=1003 ; z=8 \cdot 08$, $\mathrm{p}<0.0001)$, but the number of hernia repairs did not significantly increase $(1986-90$ mean $=1557$, $90 / 91=1590 ; z=0 \cdot 59, p=0 \cdot 55)$. The same pattern is found when data are added for the remaining two districts with valid data and only minor (less than $3 \%$ of throughput) usage of the treatment centre (Gwynedd and Gwent, combined population 670000$)$.

WAITING LISTS

Routine waiting list publications show that between March 1990 when the treatment centre

Table III Patient satisfaction with treatment (scored on an 11 point scale; $0=v e r y$ poor, $10=$ excellent )

\begin{tabular}{|c|c|c|c|c|}
\hline & \multicolumn{4}{|l|}{ Score } \\
\hline & $0-5$ & $6-8$ & $9-10$ & No reply \\
\hline \multirow{6}{*}{$\begin{array}{l}\text { Outpatient consultation } \\
\text { Preoperative care } \\
\text { Postoperative care } \\
\text { Postoperative pain relief } \\
\text { Discomfort when } \\
\text { travelling home }\end{array}$} & $2(0 \cdot 7 \%)$ & $21(7 \cdot 9 \%)$ & $244(91.4 \%)$ & 1 \\
\hline & & $21(7 \cdot 9 \%)$ & $245(91.4 \%)$ & 2 \\
\hline & $5(1.9 \%)$ & $27(10 \cdot 2 \%)$ & $234(88 \%)$ & 2 \\
\hline & $8(3 \cdot 2 \%)$ & $43(17 \cdot 2 \%)$ & $199(79 \cdot 6 \%)$ & 18 \\
\hline & $67(26 \%)$ & $90(34 \cdot 9 \%)$ & $101(39 \%)$ & 10 \\
\hline & & Yes & No & No reply \\
\hline \multirow{3}{*}{\multicolumn{2}{|c|}{$\begin{array}{l}\text { Do you think you were discharged too soon? } \\
\text { Did you have to call your GP after discharge? } \\
\text { Were you given antibiotics by your GP for } \\
\text { a wound infection? }\end{array}$}} & $66(25 \%)$ & $198(75 \%)$ & 4 \\
\hline & & $41(17 \cdot 7 \%)$ & $191(82.3 \%)$ & 36 \\
\hline & & $57(23.8 \%)$ & $182(76 \cdot 2 \%)$ & 29 \\
\hline \multirow{3}{*}{\multicolumn{2}{|c|}{$\begin{array}{l}\text { Were you satisfied with the treatment in } \\
\text { the centre? } \\
\text { Would you advise a friend or family member } \\
\text { to undergo treatment in the centre? }\end{array}$}} & & 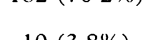 & 23 \\
\hline & & 25 & $10(3 \cdot 8 \%)$ & 5 \\
\hline & & $262(98.5 \%)$ & $4(1.5 \%)$ & 2 \\
\hline
\end{tabular}

opened and March 1991, waiting lists for nonurgent general surgery fell significantly in length in the six districts whose residents were major users of the treatment centre (March 1990-7261, March $1991-6290, \quad$ fall $=13 \cdot 4 \% ; \quad z=8 \cdot 3$, $\mathrm{p}<0.0001)$. The numbers of non-urgent cases waiting for over one year also fell significantly (March 1990-2281, March 1991-2099, fall=8\%; $\mathrm{z}=2 \cdot 75, \mathrm{p}=0 \cdot 006)$.

In an attempt to control for external trends in waiting list length, such as might arise from the administrative review or validation of waiting lists, lists in gynaecology and ear, nose, and throat (ENT) were also examined in the same districts (figure). No treatment centre provision had been made for patients in these specialties. In ENT both non-urgent waiting and non-urgent waiting over one year showed increases which fell just short of significance (4557 to $4737 ; \mathrm{z}=1.87$; $p=0.06$ and 1275 to $1366 ; z=1.77 ; p=0.08$, respectively). In gynaecology both parameters increased significantly (3058 to $3719 ; \mathrm{z}=8 \cdot 0$, $\mathrm{p}<0.0001$ and 350 to $595 ; \mathrm{z}=8.0, \mathrm{p}<0.0001$ respectively).

Further control was incorporated by making a comparison with general surgical waiting lists in the three districts (Gwynedd, Gwent, and Clwyd) that were only minor users of the treatment centre (less than 3\% throughput) (see figure). In these districts there were small but not significant increases in both overall non-urgent waiting and non-urgent waiting greater than one year (2925 to $2957 ; \mathrm{z}=0.42, \mathrm{p}=0.68$ and 492 to $528 ; \mathrm{z}=1 \cdot 13$, $\mathrm{p}=0 \cdot 26)$.

\section{PATIENT ACCEPTABILITY}

The response rate to the questionnaire given to patients was only $36 \%$ (268 of 746) and conclusions based on it must be tentative. The principal findings are shown in table III. The general level of satisfaction with the treatment centre was high, although a substantial minority $(26 \%)$ scored 5 or less for discomfort on the homeward journey. A similar proportion considered that they were discharged too early. Almost $24 \%$ reported that they were given antibiotics by their GP for wound infection. These diagnoses cannot be validated and an unknown proportion almost certainly represent wound redness in the absence of infection. Moreover, it is only slightly higher than the proportion of wound problems reported in at least one other large series of hernia and varicose vein procedures. ${ }^{18}$

\section{Discussion}

Directing substantial "ring fenced" resources to the treatment of hernias and varicose veins is innovative, but the evaluation of the effect of this expenditure is vital. This study has achieved this by making use of a natural experiment, incorporating appropriate controls. Within the inherent limitations of such a quasi experimental method, this study offers sound reasons for believing that the General Surgery Treatment Centre has met its objectives.

At the simplest level, it has attracted the contracted number of patients from a wide geographical area, and patient satisfaction has been high, albeit against the background of a poor response 
rate. Patients from the host district have made up substantially more than the intended $20 \%$, however. While the service is essentially responsive to the wishes of referring doctors, efforts are now being made to publicise the centre more widely and to encourage referrals from clinicians elsewhere.

The cost per procedure $(£ 674)$ is similar to charges for these inpatient procedures elsewhere in the NHS (varicose veins mean $£ 677$; inguinal hernia mean $£ 701$; femoral hernia mean $£ 786$ ) (South Western Regional Health Authority, personal communication).

On an "all Wales" basis the extra capacity potentially provided by the centre has been $7 \%$ for hernia operations and $25 \%$ for varicose vein procedures. It is striking that there has been no significant increase overall in the number of hernia repairs performed. Rather there is evidence that substitution has occurred, whereby an increase in hernia operations in the treatment centre has been counterbalanced by decreases elswhere in the Principality. For varicose veins, however, there has been a net increase in throughput, similar in magnitude to the extra quantum of capacity provided by the centre. A possible explanation for this is that surgeons often make specific provision for varicose vein treatment whereas hernia procedures are usually added to general operating lists. This finding alone, however, underlines the difficulty of predicting the impact that changes in provision will have upon service delivery in a complex health system.

The acid test, however, is the impact of this expenditure on surgical waiting lists. Overall there has been, during the year studied, a fall in waiting in general surgery in those districts that made substantial use of the centre. This has not been observed within the same districts in other surgical specialties with no treatment centre provision, nor has it happended in those districts which made only minor use of the centre. The support shown for the centres by, amongst others, the Parliamentary Select Committee on Welsh Affairs in its recent report on elective surgery, seems justified. ${ }^{19}$

Nonetheless this success should be kept in perspective. The decline in inpatient waiting lists has been relatively modest ( $13 \%$ overall, $8 \%$ for non-urgent waiting over one year), especially when judged against the fact that these conditions together are likely to constitute $45 \%$ of patients on these waiting lists. ${ }^{20}$ The contracted activity of the centre has, however, been substantially increased for the year 1991-92, to 1400 operations. It will be of interest to assess whether this produces a more marked decline in waiting.

An important question which this study is unable to address concerns the level of provision that will be necessary to prevent the re-emergence of prolonged waiting for these conditions when and if the existing backlog is cleared. Nor have data been systematically collected as yet on long term outcome and recurrence rates.

On the strength of this evidence serious consideration should be given to establishing such centres more widely in the UK as an acceptable (to both patients and clinicians) and effective contribution to the problem of surgical waiting lists.

We would like to acknowledge the invaluable assistance of the staff of the Surgical Treatment Centre and of the Health Intelligence Unit of the Welsh Health Common Services Authority in making data available. We thank Dr Tim Peters for statistical advice.

1 Powell JE. Medicine and politics: 1975 and after. London: Pitman, 1976

2 Yates J. Why are we waiting?. Oxford: Oxford University Press, 1987

3 Cullis JG, Jones PR. Inpatient waiting: a discussion and policy proposal. $B M F$ 1983; 287: 1483-86.

4 Chew R. Health expenditure in the UK. London: Office of Health Economics, 1986.

5 Frankel S. The natural history of waiting lists: some wider explanations for an unnecessary problem. Health Trends 1989; 21: 56-8.

6 Gudex C, Williams A, Jordan $M$ et al. Prioritising waiting lists. Health Trends 1990; 22: 103-8.

7 Morris D. Surgical waiting lists. BMF 1984; 289: 271-72.

8 Goldacre MJ. Lee A, Don B. Waiting list statistics. I: relation between admissions from waiting list and length of waiting list. $B M \mathcal{F}$ 1987; 295: 1105-8.

9 Fowkes FGR, Page SM, Phillips-Miles D. Surgical Fowkes FGR, Page SM, Phillips-Miles D. Surgical
manpower, beds and output in the NHS: $1967-1977 . B r f$ Surg 1983; 70: 114-6.

10 Buttery RB, Snaith AH. Surgical provision, waiting times and waiting lists. Health Trends 1980; 12: 57-61.

11 Secretary of State for Health. Working for patients. London: HMSO, 1989.

12 Thomas HF, Darvell RHJ, Hicks C. Operation cataract: a means of reducing waiting lists for cataract operations. $B M \mathcal{F}$ 1989; 299: 961-63.

13 Frankel S. Health needs, health-care requirements, and the myth of infinite demand. Lancet 1991; 337: 1588-90.

14 Richardson A, Charny M, Hanmer-Lloyd S. Public opinion and purchasing. BMF $1992 ; 304$ : $680-82$.

15 Klein R. NHS reforms: the first six months. BMF 1992; 304: 199-200.

16 Last JM (ed). A dictionary of epidemiology. Oxford: Oxford University Press, 1988

17 Armitage P, Berry G. Statistical methods in medical research. Oxford: Blackwell, 1987.

18 Goldbourne IA, Ruckley CV. Operations for hernia and varicose veins in a day-bed unit. $B M F 1979 ; 2: 712-14$.

19 House of Commons Welsh Affairs Committec. Report on House of Commons Welsh Affairs Committe.
elective surgery. Vol 1. London: HMSO, 1991.

20 Davidge M, Vickerstaff L, Harley M, Yates J. The anatomy of large inpatient waiting lists. Lancet 1987; i: 794-6. 